\title{
Mortalin-p53 interaction in cancer cells is stress dependent and constitutes a selective target for cancer therapy
}

\author{
W-J Lu', NP Lee ${ }^{1}$, SC Kaul ${ }^{2}$, F Lan ${ }^{3}$, RTP Poon ${ }^{1}$, R Wadhwa ${ }^{\star, 2}$ and JM Luk ${ }^{\star, 1,4,5}$
}

\begin{abstract}
Stress protein mortalin is a multifunctional protein and is highly expressed in cancers. It has been shown to interact with tumor suppressor protein-p53 (both wild and mutant types) and inactivates its transcriptional activation and apoptotic functions in cancer cells. In the present study, we found that, unlike most of the cancer cells, HepG2 hepatoma lacked mortalin-p53 interaction. We demonstrate that the mortalin-p53 interaction exists in cancer cells that are either physiologically stressed (frequently associated with p53 mutations) or treated with stress-inducing chemicals. Targeting mortalin-p53 interaction with either mortalin small hairpin RNA or a chemical or peptide inhibitor could induce p53-mediated tumor cell-specific apoptosis in hepatocellular carcinoma; p53-null hepatoma or normal hepatocytes remain unaffected.
\end{abstract}

Cell Death and Differentiation (2011) 18, 1046-1056; doi:10.1038/cdd.2010.177; published online 14 January 2011

The wild-type p53 is a key tumor suppressor protein that eliminates genetically unstable cells by inducing either cell cycle arrest or apoptosis through transcriptional regulation or direct interaction with apoptotic proteins. ${ }^{1,2}$ Functional inactivation of $\mathrm{p} 53$, a frequent event in cancer cells, occurs by three main mechanisms: (i) mutations, (ii) post-translational modifications and (iii) cytoplasmic sequestration ${ }^{3-5}$ by its binding proteins. Although several cellular proteins are shown to interact with $\mathrm{p} 53$, the mechanism of its inactivation still remains unclear. Furthermore, interaction of p53 with its binding partners is context dependent, and influenced by both intracellular and extracellular environment. Cellular stress response (intrinsic and extrinsic) has been shown to evoke p53 signaling $^{6}$ through its modifications, including phosphorylation (at serine and/or threonine), ${ }^{7}$ acetylation, ${ }^{8}$ sumoylation, ${ }^{9}$ glycosylation, ${ }^{10}$ ribosylation ${ }^{11}$ or ubiquitylation. ${ }^{12}$ Furthermore, it has been shown that p53 protein interacts with several stress proteins, including Hsp40, Hsp70, Hsp84, Hsp90, DnaK, DnaJ and GrpE in vivo, ${ }^{13-15}$ that potentially modulate p53 activities. However, their roles in development and progression of cancer, physiologically a stressed condition, remain unclear.

Mortalin/mthsp70/GRP75/PBP74, a member of the heat shock protein (Hsp) 70 family, is enriched in human cancer cells. ${ }^{16-18}$ Overexpression of mortalin was sufficient to increase the malignancy of breast cancer cells in both in vitro and in vivo models. The underlying mechanism was shown to be the sequestration of wild-type p53 in the cytoplasm, leading to inhibition of its transcriptional activation and control of centrosome duplication functions. ${ }^{19-22}$ A cationic inhibitor (MKT-077) of mortalin that releases p53 from mortalin-p53 complex was shown to cause activation of p53 and growth arrest of cancer cells. ${ }^{23}$ Similarly, mortalin-binding p53 peptides caused nuclear translocation and activation of p53. ${ }^{19}$ Mortalin was identified as a marker for hepatocellular carcinoma (HCC) metastasis and recurrence by proteomics analysis of matched tumor and non-tumor tissues,$^{18}$ suggesting that it contributes to HCC development and recurrence.

In the present study, we found that unlike most cancer cells, HepG2 hepatoma lacked mortalin-p53 interaction. Using HepG2 as a model, we demonstrate that the mortalin-p53 interaction that causes inactivation of p53-mediated apoptosis depends on the cellular stress level. Unstressed or weakly stressed cancer and normal cells lack mortalin-p53 interaction. Furthermore, mortalin small hairpin RNA (shRNA) could reactivate $\mathrm{p53}$-mediated apoptosis selectively in cancer cells. These findings open the possibilities for clinical application of mortalin shRNA, mortalin-p53 binding antagonists or their combination with chemotherapeutic drugs in the HCC treatment.

\section{Results}

Human HepG2 cells lacked mortalin-p53 interaction and were resistant to mortalin shRNA-induced apoptosis. Mortalin-specific shRNA-2166 was designed

\footnotetext{
${ }^{1}$ Department of Surgery, Li Ka Shing Faculty of Medicine, The University of Hong Kong, Hong Kong, China; ${ }^{2}$ National Institute of Advanced Industrial Science \& Technology (AIST), Central 4, 1-1-1 Higashi, Tsukuba, Ibaraki 305 8562, Japan; ${ }^{3}$ Department of Medicine, Division of Cardiology, Stanford University School of Medicine, Stanford, CA 94305, USA; ${ }^{4}$ Department of Pharmacology and Department of Surgery, National University Health System, National University of Singapore, Singapore 117597, Singapore and ${ }^{5}$ Cancer Science Institute, National University of Singapore, Singapore 117597, Singapore

*Corresponding author: R Wadhwa, National Institute of Advanced Industrial Science \& Technology (AIST), Central 4, 1-1-1 Higashi, Tsukuba, Ibaraki 3058562 , Japan. Tel: + 8129861 9464; Fax: + 8129861 2900; E-mail: renu-wadhwa @aist.go.jp or JM Luk, Department of Pharmacology, National University Health System, National University of Singapore, MD-11 \#05-09, 10 Medical Drive, Singapore 117597, Singapore. Tel: + 656516 4516; Fax: +65 6873 7690; E-mail: jmluk@nus.edu.sg Keywords: stress; mortalin-p53 interaction; cancer; target; therapy

Abbreviations: shRNA, small hairpin RNA; Hsp70, heat shock protein 70; HCC, hepatocellular carcinoma; GRP78, glucose-regulated protein 78; MKT-077, 1-ethyl-2[[3-ethyl-5-(3-methylbenzothiazolin-2-yliden)]-4-oxothiazolidin-2-ylidenemethyl]pyridinium chloride; MTT, 3-(4,5-dimethylthiazol-2-yl)-2,5-diphenyltetrazoliumbromide Received 26.7.10; revised 27.10.10; accepted 08.11.10; Edited by JC Marine; published online 14.1.11
} 
a

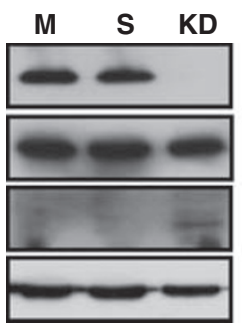

PLC/PRF/5

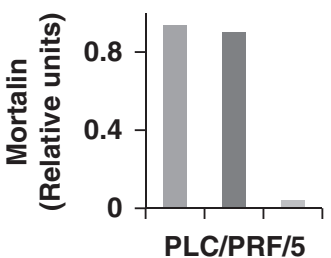

b

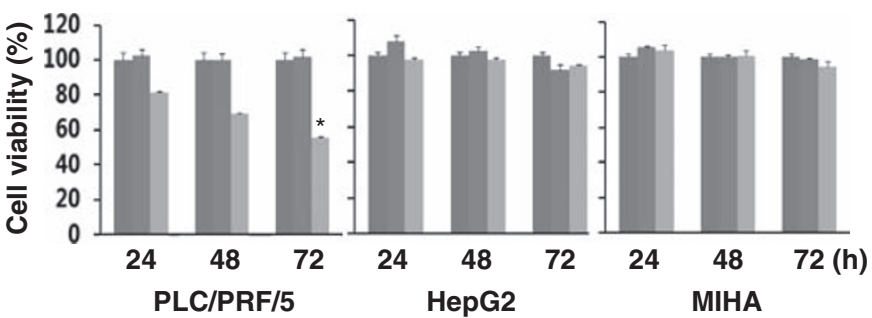

e

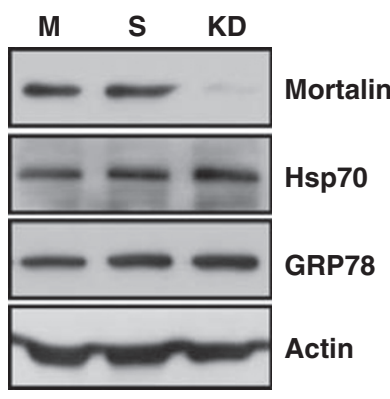

HepG2
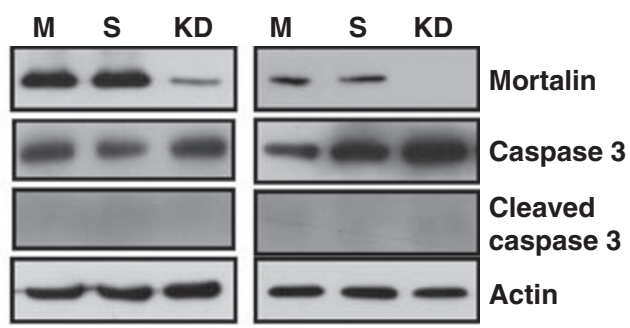

MIHA mock ncramble

knockdown

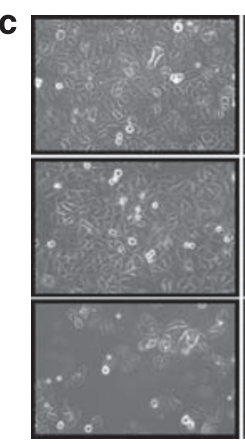

PLC/PRF/5

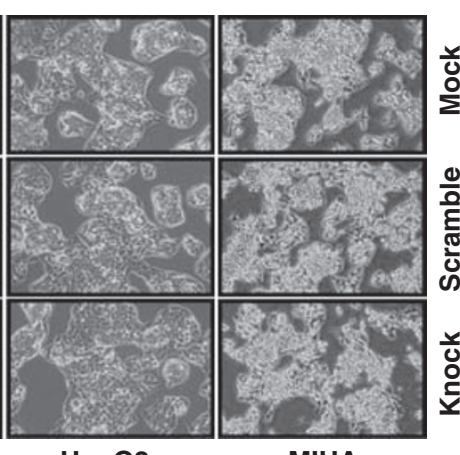

MIHA
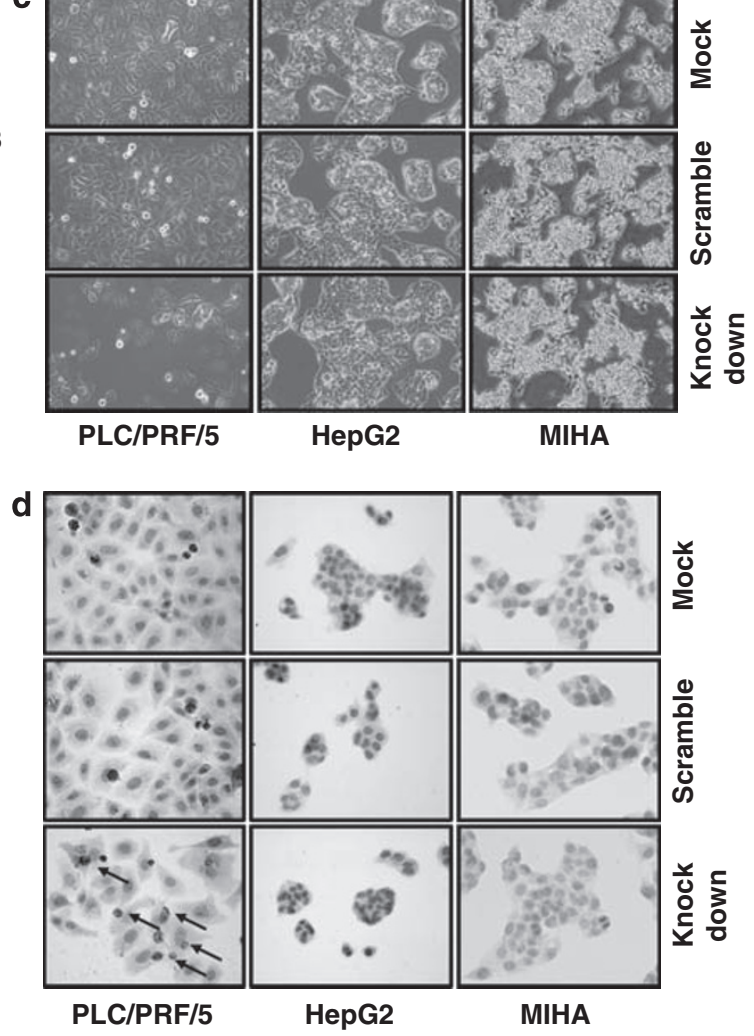

g

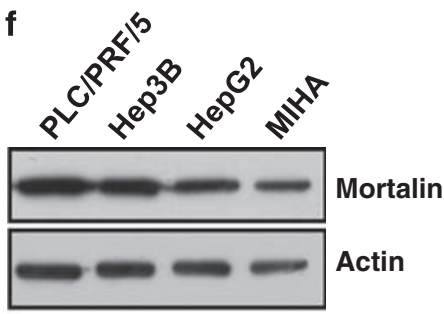

Cytosolic

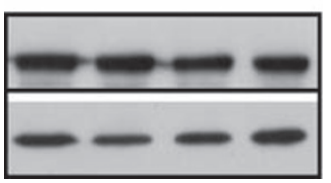

Mitochondria

Mortalin

Cytochrome C

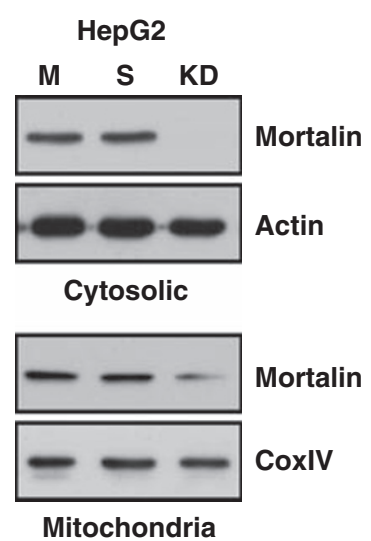

Figure 1 Mortalin silencing induces apoptosis in PLC/PRF/5, but not in MIHA and HepG2 cells. (a) Mortalin shRNA caused reduction in mortalin expression (KD) in all the three cell lines (examined at $72 \mathrm{~h}$ post transfection); empty vector transfected (Mock-M) and scrambled shRNA transfected (S) cells were used as control. (b) Viability (MTT assay) was significantly reduced in PLC/PRF/5 $\left({ }^{*} P<0.05\right)$ at $72 \mathrm{~h}$ post-transfection of mortalin shRNA; MIHA cells and HepG2 did not show any change as compared with controls. (c) Phase-contrast images of control and mortalin shRNA transfected cells showing apoptosis in mortalin shRNA transfected PLC/PRF/5 cells only. (d) In situ TUNEL staining identified mortalin shRNA-induced apoptosis in PLC/PRF/5, but not in MIHA and HepG2 cells. Apoptotic PLC cells are marked with arrows. (e) Mortalin knockdown cells (KD) were examined for Hsp70 and glucose-regulated protein 78 (GRP78) by western blotting with specific antibodies. The mortalin shRNA-2166 was highly specific for mortalin and did not cause any reduction in Hsp70 and GRP78. (f) Presence of mortalin in the cytoplasmic and mitochondrial fractions in four cell lines was examined by western blotting with mortalin specific antibody. (g) Mortalin knockdown by shRNA-2166 caused reduction in mortalin in both cytosolic and mitochondrial fractions

and used to intervene mortalin-p53 interaction in cancer cells. HCC cell line PLC/PRF/5 (PLC) (mutant p53-249 serine mutation, the most common p53 mutation site in $\mathrm{HCC}$ with $\mathrm{G}: \mathrm{C}$ to $\mathrm{T}: \mathrm{A}$ transversion) transfected with shRNA-2166 showed mortalin suppression and dramatic reduction (almost $50 \%$ ) in cell viability (Figures 1a and b). However, although immortalized human hepatocytes MIHA and HepG2 hepatoma showed $70-90 \%$ knockdown of mortalin expression, their viability was not affected (Figures 1a and b). On the basis of the cell morphology and the rapidly reduced cell viability, it appeared that the shRNA-2166 led the cells to apoptosis, which was further confirmed by the presence of caspase cleavage and deoxynucleotidyl transferase-mediated dUTP nick end labeling (TUNEL) staining (Figures 1a, c and d). 
Of note, consistent with the cell viability data (Figure 1b), apoptosis was not observed in MIHA and HepG2 cells, and they were negative for both caspase cleavage and TUNEL staining (Figures 1a, c and d). We first confirmed that mortalin shRNA2166 was specific and did not crossreact with other mRNAs (Hsp70, glucose-regulated protein 78) that show close homology to mortalin. As shown in Figure 1e, we confirmed that shRNA2166 was specific to mortalin. Mortalin was earlier shown to sequester p53 in the cytoplasm and inactivate its transcriptional activities. On the basis of this finding, mortalin shRNA-2166induced reduction in mortalin expression was expected to cause nuclear translocation and activation of p53, possibly resulting in apoptosis as seen in Figures 1a-d. We further examined whether mortalin was present in the cytosolic fractions of these cell lines. Similar to several other cell lines, ${ }^{24,25}$ all the four HCC lines used in this study showed mortalin in both the cytosolic and mitochondrial fractions (Figure 1f). Furthermore, shRNA-2166 caused reduction in both the cytosolic and mitochondrial fractions (Figure 1g).

In order to confirm that the apoptosis induced by mortalin shRNA was p53 dependent, we carried out p53 knockdown in combination with mortalin knockdown. As expected and shown in Figures $2 a-c$, the efficacy of mortalin silencinginduced apoptosis was significantly compromised by p53 knockdown and by treatment with a specific inhibitor (PFT- $\mu$ ) of p53. ${ }^{26}$ The data confirmed that the knockdown of mortalininduced apoptosis was p53 dependent. In order to demonstrate that the effect was specific to mortalin shRNA, we also performed Hsp60 knockdown and found no apoptosis either in PLC or in HepG2 cells (Figures $2 d-f$ ). As PFT- $\mu$ was shown to be an inhibitor of Hsp70 (HSPA1A/B), ${ }^{27}$ we confirmed that mortalin shRNA-2166 did not cause any effect on Hsp70 (Figure 1e). We also performed the knockdown of Hsp70 and of mortalin together. Hsp70 knockdown caused a low level of apoptosis (about $5-10 \%$ as compared with the $40-50 \%$ caused by mortalin knockdown). The effect of two knockdowns (mot-shRNA and Hsp70-shRNA) was synergistic, and the apoptosis caused by mortalin knockdown was rescued by PFT- $\mu$ (Figures $2 \mathrm{~g}$ and $\mathrm{h}$ ). These data demonstrated that the mortalin shRNA-induced apoptosis was p53 dependent. Hence, HepG2 cells that were resistant to the apoptotic activity of mortalin shRNA may lack mortalin-p53 interaction. We, therefore, examined the interaction of mortalin and p53 by co-immunoprecipitation assay. As seen in Figure $3 a$, mortalin immunocomplexes contained p53 in PLC, but not in MIHA and HepG2 cells; Hep3B (p53 null) cells were used as a control. Specificity of the mortalin antibody was confirmed by probing the mortalin immunocomplexes with anti-Hsp70 antibody. As shown in Figure 3b, mortalin antibody was specific and did not pull down any Hsp70. Double immunostaining was performed, and we found that the knockdown of mortalin by mortalin-specific shRNA-2166 led to nuclear translocation of p53 in PLC cells only. MIHA and HepG2 that lacked mortalin-p53 interaction did not show any change in subcellular localization of p53 (Figure 3c), suggesting that mortalin shRNA-induced apoptosis is dependent on mortalinp53 interactions.

Cellular stress is a key determinant of mortalin-p53 interactions and apoptosis. On the basis of the above data, we hypothesized that the interaction of mortalin and p53 may be stress dependent. Hence, we examined the stress-induced phosphorylation of p53 and its interaction with mortalin in a panel of HCC cells. The phosphorylation of p53 was detected at three (Ser 15, Ser 37, Ser 392) of the seven sites in five HCC cell lines (97H, 97L, H2P, H2M, PLC) (Figure 4a). Interestingly, these five cell lines underwent apoptosis by shRNA-2166 (Figure1 and data not shown). Furthermore, silencing of mortalin enhanced p53 phosphorylation at one or more sites (Figure 4b). The two cell lines (HepG2, MIHA) that were not affected by silencing of mortalin showed a low level of stress status (lower level of p53 accumulation and phosphorylation).

In order to confirm further that the interaction of mortalin and p53 is stress dependent, we exposed HepG2 cells to low doses of cisplatin (a platinum-based chemotherapeutic drug to induce DNA cross-linking and damages). By cell cycle analysis, we confirmed that the low doses $(1-2 \mu \mathrm{g} / \mathrm{ml})$ did not cause any growth arrest of cells (data not shown). As shown in Figure 5a, the levels of both mortalin and p53 were found to increase in response to the cisplatin treatment $(>2 \mu \mathrm{g} / \mathrm{ml})$ (Figure 5a), and p53 was phosphorylated at Ser 15 (Figure 5c). Of note, consistent with our model, we found that cisplatin treatment induced the mortalin-p53 interaction in HCC cells (Figure 5b). Whereas mortalin immunocomplexes lacked p53 in control HepG2 cells, cisplatin-treated cells showed co-precipitation of p53 with mortalin (Figure 5b). Most interestingly, we found that the cisplatin-treated cells were sensitized to mortalin sh-2166-induced apoptosis mediated by cleavage of caspase 3 (Figures $5 \mathrm{c}$ and $\mathrm{d}$ ). Cleaved caspase 3 was not detected in control (vector-transfected and cisplatin-treated) groups, demonstrating that the apoptosis was not directly induced by cisplatin at suboptimal dosage used in the present experiment. Instead, it was marked by an increased phosphorylation of p53 at Ser 15 and cleavage of caspase 3 (Figure 5c), as also detected in mortalin shRNAresponsive cell lines shown in Figures 1 and 3 . These data demonstrated that the mortalin-p53 interaction occurs in stressed cancer cells, and may serve as an effective target for cancer therapy. In order to confirm that the cisplatin and mortalin shRNA-induced apoptosis (Figures $5 c$ and d) was mediated by $p 53$, we recruited p53 shRNA and p53 inhibitor to rescue the apoptosis in HepG2 cells. As shown in Figure 5e, the apoptosis induced by the combination of cisplatin and mortalin shRNA was significantly reduced (about $80 \%$ ) either by p53 shRNA or by treatment with p53 inhibitor. In order to prove that the mortalin-p53 interaction was not restricted to cisplatin, we also recruited two other kinds of stress-inducing reagents-hydrogen peroxide (generating free radicals) and doxorubicin (cytotoxic anthracycline antibiotics). As shown in Figure 6, similar to cisplatin, both of these agents caused apoptosis of cells in combination with mortalin shRNA.

Targeting mortalin-p53 interactions reactivates p53-dependent apoptotic pathway in stressed cancer cells. We next targeted mortalin-p53 interaction by a small molecule (MKT-077, a cationic rhodacyanine dye) and a peptide ( $\mathrm{p} 53^{312-352}$, carboxy-terminal amino-acid resides 312-352 of p53), previously shown to bind to mortalin and reactivate wild-type $p 53$, leading to growth arrest. ${ }^{19,}{ }^{23}$ When 


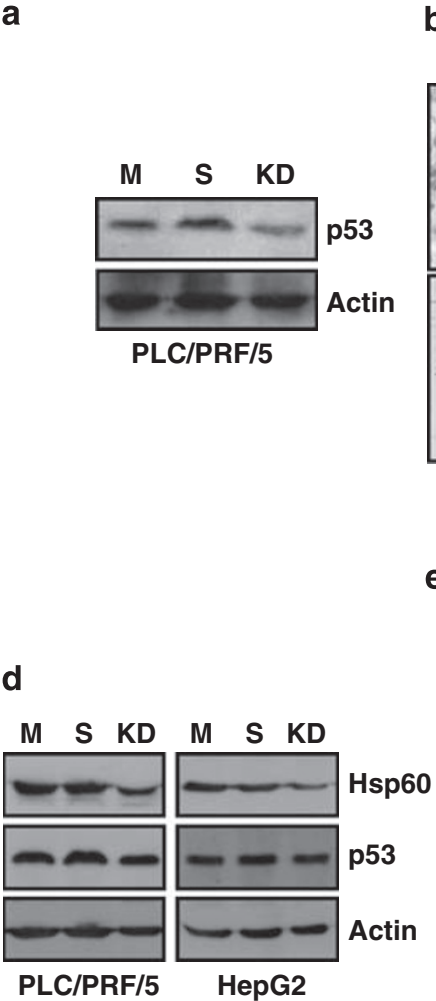

b
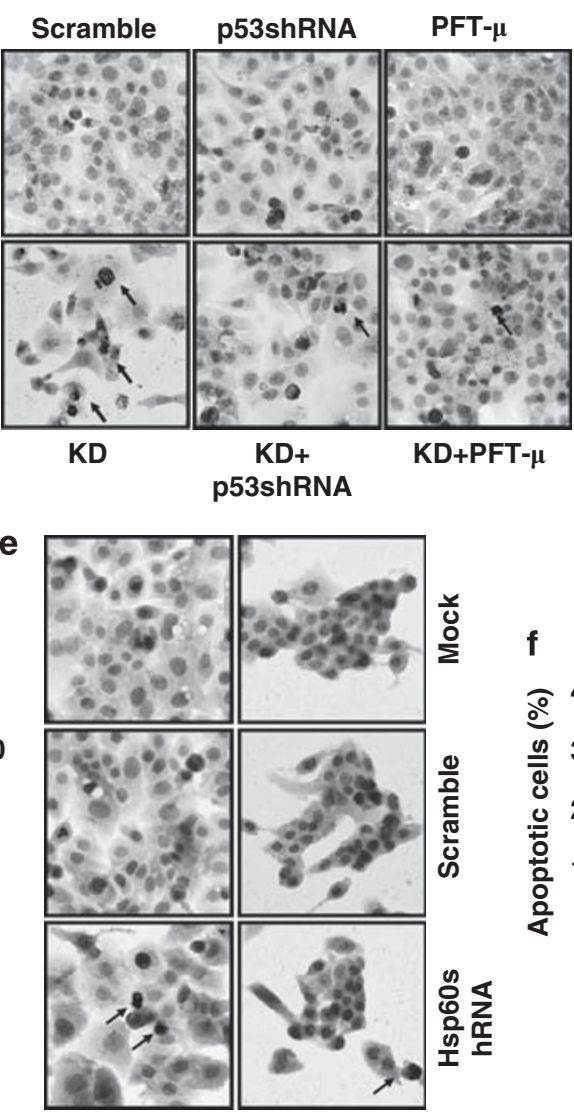

PLC/PRF/5
PLC/PRF/5
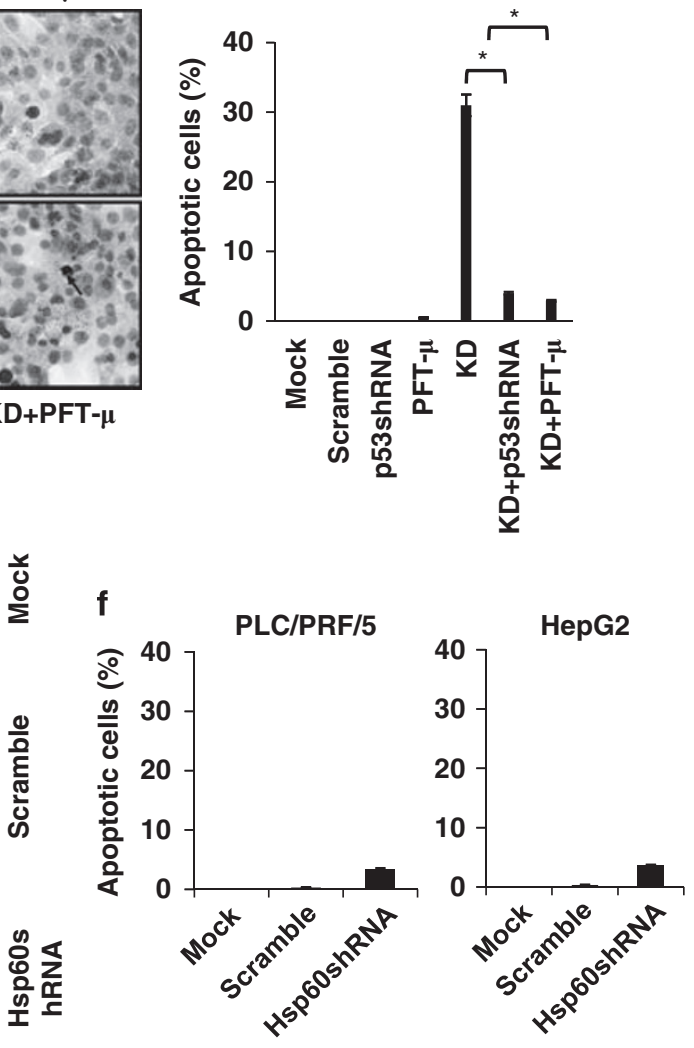

g
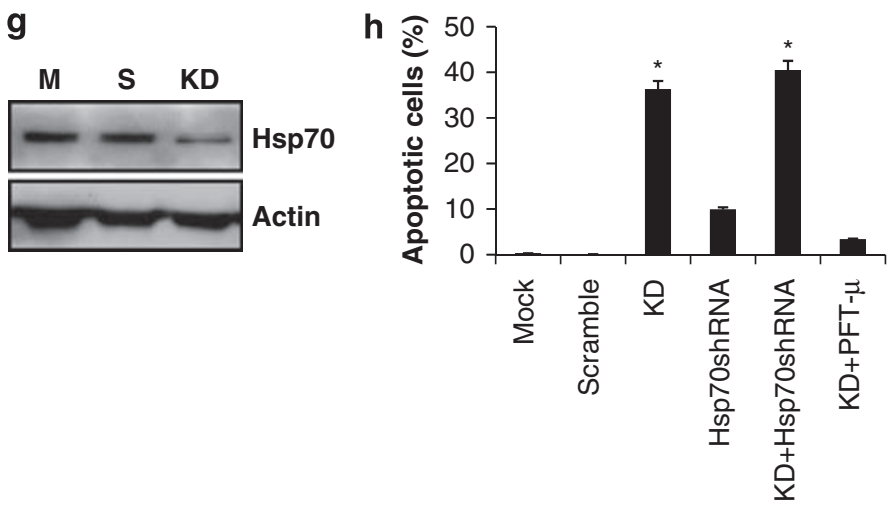

Figure 2 Mortalin silencing-induced apoptosis could be rescued by p53 shRNA and p53-specific inhibitor. (a) Western blot showing p53 knockdown with p53 shRNA in PLC/PRF/5 cells. (b) In situ TUNEL staining showing that mortalin knockdown (KD)-induced apoptosis was significantly compromised by treatment with p53 shRNA and p53specific inhibitor (PFT- $\mu$ ) in PLC/PRF/5 cells. (c) Quantitation of apoptotic cells is shown $\left({ }^{*} P<0.05\right)$. (d) Western blot showing Hsp60 knockdown. (e) In situ TUNEL staining showing that Hsp60 knockdown did not induce apoptosis. (f) Quantitation of apoptotic cells is shown. (g) Cells transfected with Hsp70 shRNA showed reduction in Hsp70 protein. (h) Mortalin knockdown (KD) showed higher level of apoptosis as compared with the Hsp70 knockdown cells, and mortalin knockdown-induced apoptosis was recovered by co-treatment with PFT- $\mu$ cells $\left({ }^{\star} P<0.05\right)$. Arrows in $\mathbf{b}$ and $\mathbf{e}$ show the apoptotic cells

subjected to MKT-077 or p53 ${ }^{312-352}$ peptide expression, PLC cells (high level of stress as indicated by mutant and phosphorylated p53) underwent apoptosis (Figure 7a). Even with $30-40 \%$ efficiency of transient transfections, approximately 12-30\% apoptotic cells were observed (Figures $7 \mathrm{a}$ and $\mathrm{c}$ ) at $24-48 \mathrm{~h}$ post-treatment or posttransfection, respectively. Consistent with the occurrence of apoptosis, nuclear translocation and accumulation of p53 were observed (data not shown). In contrast to PLC cells, HepG2 cells that lacked mortalin-p53 interactions (Figure 3) did not show any apoptosis either with $\mathrm{p} 53^{312-352}$ peptide or with MKT-077 inhibitor (Figures 7a and b). However, when these cells were co-treated with the low dose $(2 \mu \mathrm{g} / \mathrm{ml})$ of cisplatin (stress inducer) that induced mortalin-p53 
a

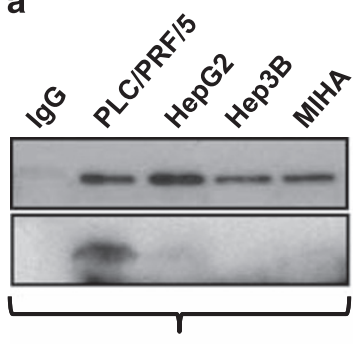

Mortalin immunocomplexes

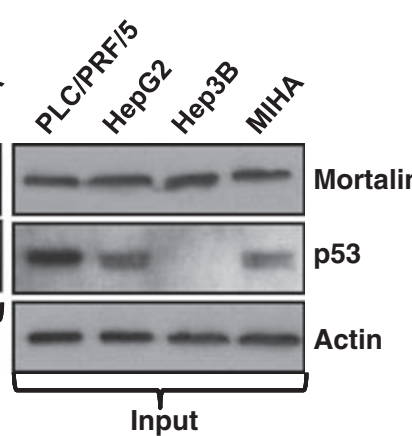

b
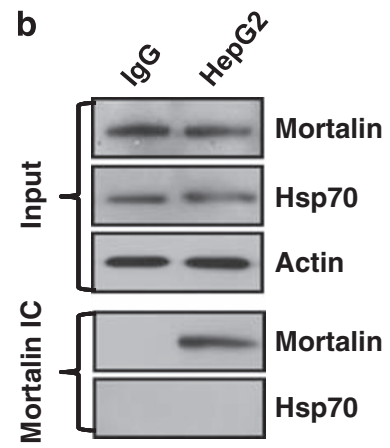

Mortalin

Hsp70

HepG2

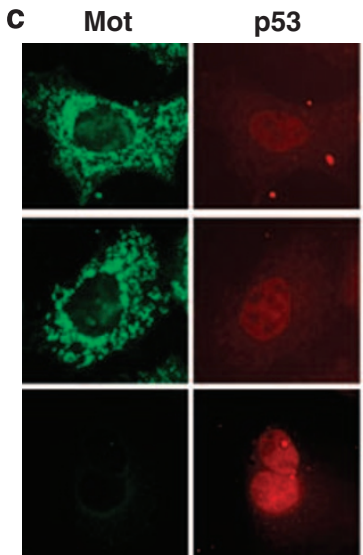

PLC/PRF/5
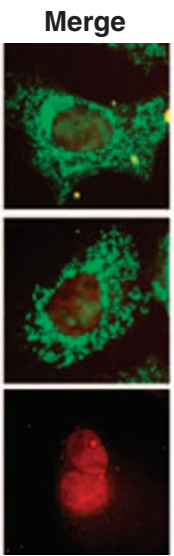
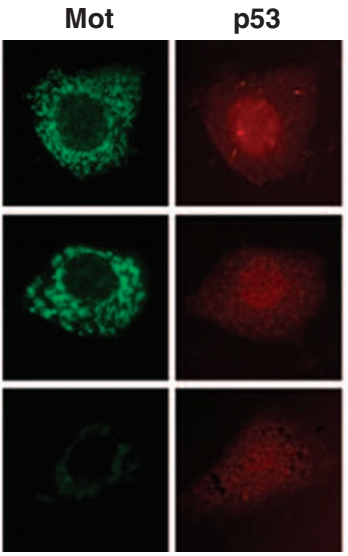

HepG2
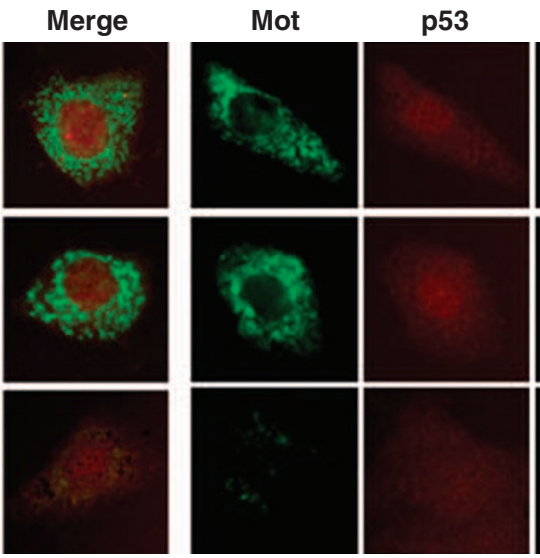

MIHA

Figure 3 Mortalin-p53 interaction was detected only in PLC, but not in MIHA and HepG2 cells. (a) p53 was detected in mortalin immunocomplexes in PLC/PRF/5. HepG2, Hep3B and MIHA cells lacked this interaction. (b) Mortalin antibody used for immunoprecipitation was specific for mortalin and did not crossreact with Hsp70. (c) Mortalin (green) knockdown induced nuclear translocation of p53 (red) in PLC cells. HepG2 and MIHA cells did not show nuclear translocation of p53 after mortalin knockdown (examined at $72 \mathrm{~h}$ post-transfection)

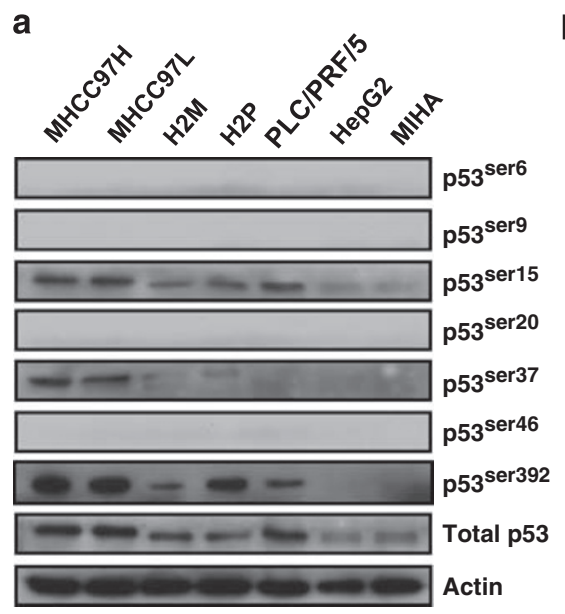

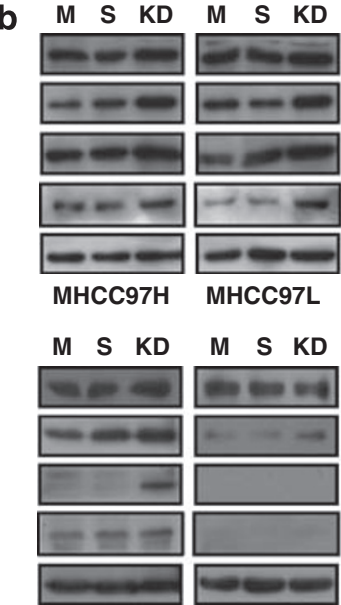

PLC/PRF/5
HepG2

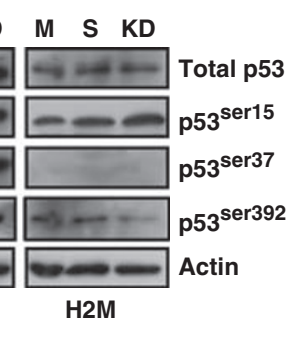

$M \quad S \quad K D$

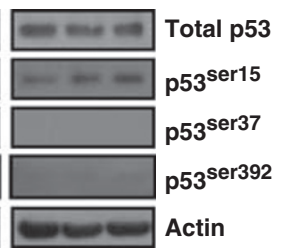

MIHA

Figure 4 Mortalin shRNA-induced apoptosis depends on mortalin-p53 interaction that in turn depends on the level of cellular stress reflected by p53 phosphorylation. (a) p53 phosphorylation at seven common phosphorylation sites was detected in six HCC and one normal immortalized liver cell line, MIHA. Strong phosphorylation signals at three phosphorylation sites (Ser 15, Ser 37, Ser 392) were detected in 97H, 97L, H2M, H2P and PLC/PRF/5 as compared with HepG2 and MIHA cells, suggesting that the former four cell lines represent cases of higher physiological stress level. (b) Mortalin shRNA-2166 caused an increase in p53 phosphorylation at one or more sites in four HCC cell lines; HepG2 and MIHA did not show any change in p53 phosphorylation (examined at $72 \mathrm{~h}$ post-transfection)

interaction (Figure 5), apoptosis and growth arrest were induced. Whereas apoptotic index was less than $3 \%$ in HepG2 cells in response to MKT-077 treatment $(24 \mathrm{~h})$ or p53 $312-352$ expression (48 h), it increased to approximately $11-13 \%$ and $21-24 \%$ by cisplatin treatment, respectively. Double immunostaining showed nuclear accumulation of p53 


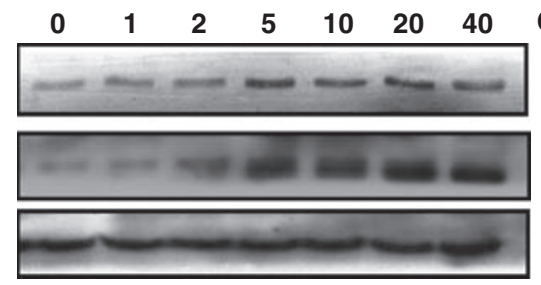

Cisplatin $\mu \mathrm{g} / \mathrm{ml}$

Mortalin

p53

Actin

Input b

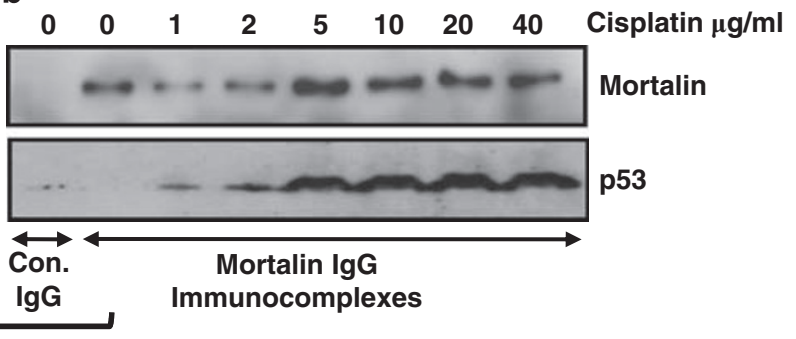

HepG2

C

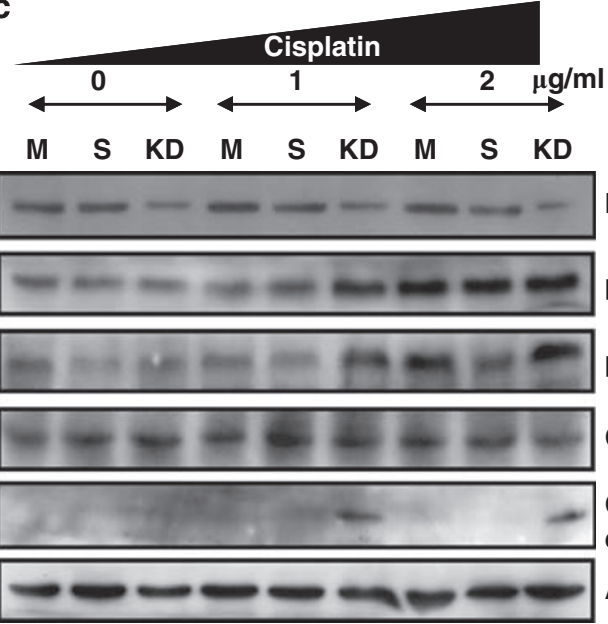

HepG2
Mortalin

p53

p53 $3^{\text {ser15 }}$

Caspase-3

Cleaved-

caspase-3

Actin

e

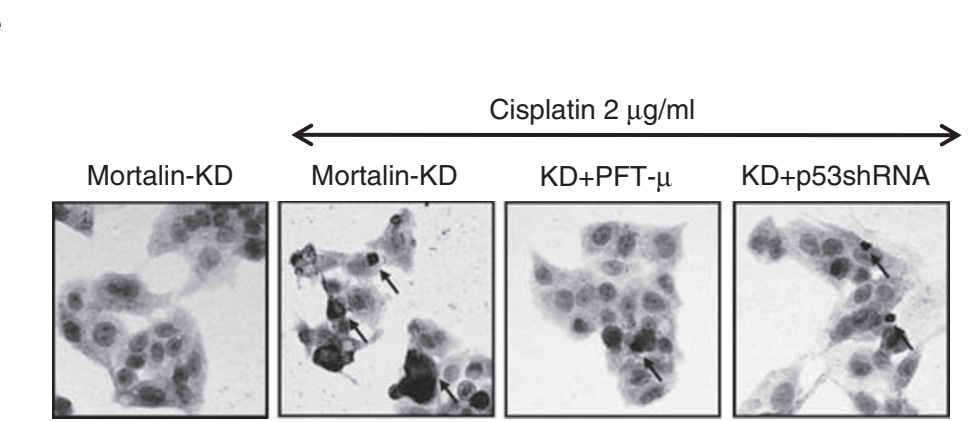

d

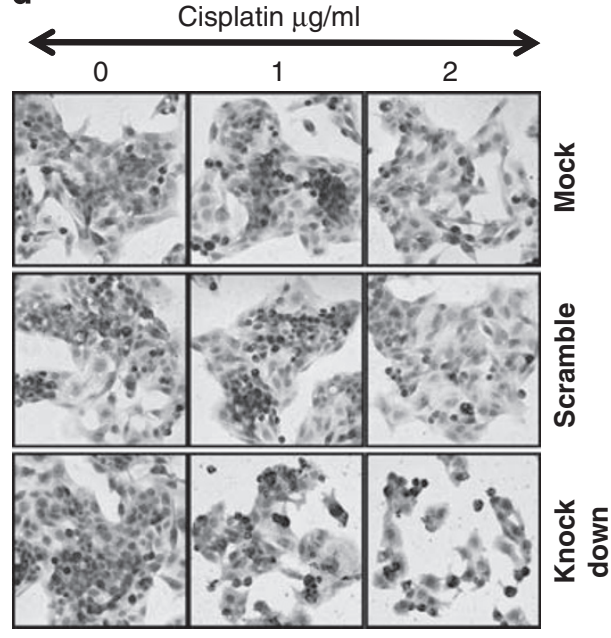

- Cisplatin $0 \mu \mathrm{g} / \mathrm{ml}$

- Cisplatin $1 \mu \mathrm{g} / \mathrm{ml}$

- Cisplatin $2 \mu \mathrm{g} / \mathrm{ml}$
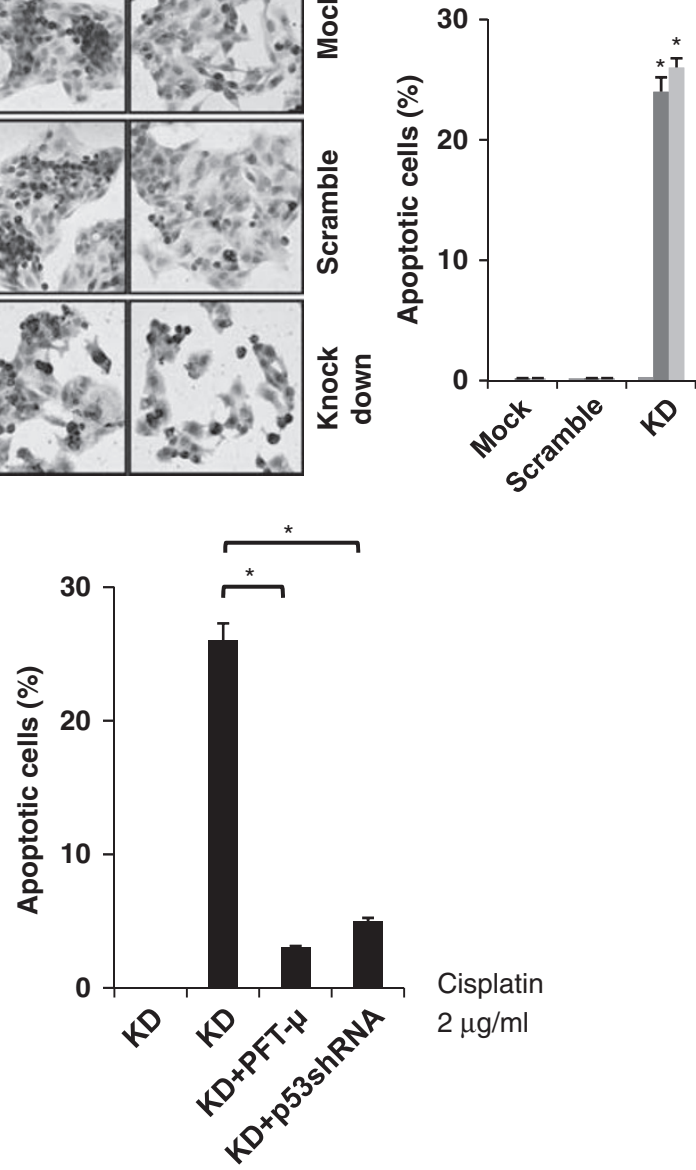

Figure 5 Mortalin-p53 interaction is induced by stress. (a) Exposure of HepG2 cells to cisplatin caused increase in p53 and mortalin. (b) Mortalin-p53 interaction was induced in HepG2 cells by cisplatin treatment (48h). (c) HepG2 cells were sensitized to mortalin shRNA-induced apoptosis after cisplatin stress-induced mortalin-p53 interactions. Cisplatin-treated cells showed increase in p53-serine15 phosphorylation and caspase 3 cleavage when co-treated with mortalin shRNA-2166 (KD). (d) In situ TUNEL staining of HepG2 cells corresponding to Figure 3c. Apoptosis was observed in cisplatin ( 1 and $2 \mu \mathrm{g} / \mathrm{ml}$ ) and mortalin shRNA-2166 (knockdown) cells only. Quantitation of apoptotic cells is shown ( $\left.{ }^{*}<<0.05\right)$. (e) Apoptosis induced by mortalin knockdown $(K D)$ and cisplatin treatment was rescued by either p53 knockdown with p53 shRNA or with a specific inhibitor of p53 (PFT- $\mu$ )

in HepG2 cells when treated with cisplatin and MKT-077 (targeting mortalin-p53 interaction) (Figure 8a). Similarly, cells transfected with mortalin-p53 binding antagonist peptide $\left(\mathrm{p} 53^{312-352}\right)$ showed nuclear accumulation of p53 only when treated with cisplatin (Figure 8b).
These data were consistent with our model shown in Figure 9. It proposes that (panel a) normal, immortalized and non-malignant cancer cells have low p53 level that does not interact with mortalin. p53 freely translocates from cytoplasm to nucleus. Mortalin knockdown has no or minimal effect in this 
a

\section{Control}
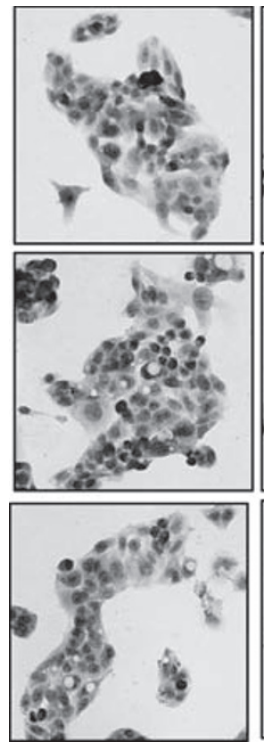

$\mathrm{H}_{2} \mathrm{O}_{2}$ $10 \mu \mathrm{M}$
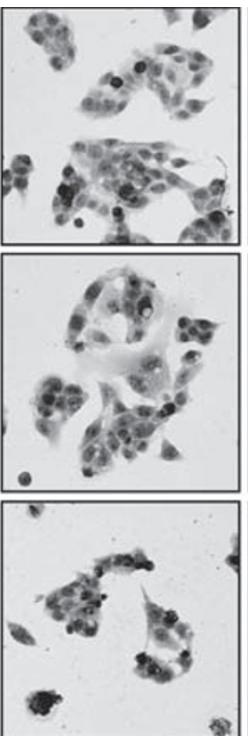

Dox $10 \mathrm{ng} / \mathrm{ml}$
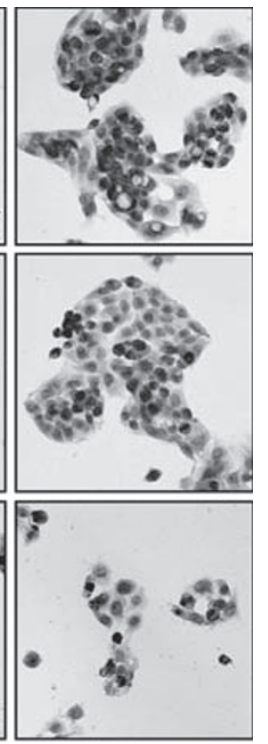

b

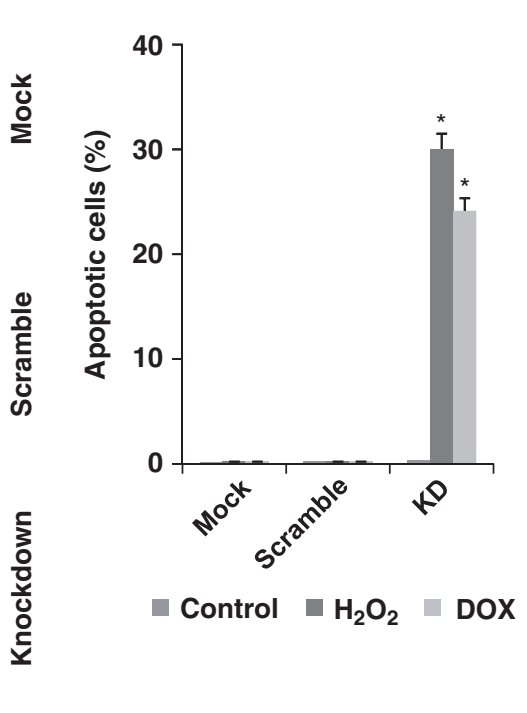

Figure 6 HepG2 cells were sensitized to mortalin knockdown-induced apoptosis by stress treatment. (a) In situ TUNEL staining showing both $\mathrm{H}_{2} \mathrm{O}_{2}$ (oxidative stress) and doxorubicin (DNA damage stress) treatment $(48 \mathrm{~h})$ caused apoptosis of HepG2 cells in combination with mortalin shRNA. (b) Quantitation of apoptotic cells is shown $\left({ }^{\star} P<0.05\right)$

category of cells; (panel b) mortalin-p53 interaction is induced by cellular stress. Cells exposed to genotoxic or malignancy stress have mortalin-p53 interaction, resulting in abrogation of apoptotic ability of p53. In these cells, mortalin knockdown causes nuclear translocation and activation of p53; finally, (panel c) malignant cancer cells are physiologically stressed and accumulate p53 (mutant) that is inactivated by its interaction with mortalin. In these cells, mortalin knockdown causes nuclear translocation of p53 leading to apoptotic death of cells. According to the proposed model and our present findings, mortalin-p53 interaction is selective for stressed cancer cells, and hence could serve as a safe target for cancer therapeutics. Mortalin shRNA could activate p53-dependent apoptosis selectively in cancer cells either by itself (PLC/PRF/ 5 cells, Figure 1) or in combination with stress-inducing agent (HepG2, Figures 5 and 6).

We next investigated the mechanism of mortalin shRNAinduced p53-dependent apoptosis. Hep3B (p53-null) cells transfected with either wild-type or mutant p53-expressing plasmids were examined for wild-type p53-specific reporter activity. We found that the silencing of mortalin resulted in increased transactivation function of wild-type p53. However, mutant p53 did not show any wild-type p53-transcriptional activity (Lu et al, data not shown). On the basis of these data, we concluded that the mutant p53-mediated apoptosis was independent of its transactivation function. We further investigated whether mortalin knockdown could cause an increase in p53-Bax interactions that may cause apoptosis. Hep3B cells transfected with either wild-type or mutant p53 were examined for p53-Bax and p53-Bcl-2 complexes. As shown in Figures $8 \mathrm{c}$ and d, we found that the interaction of p53 and Bax increased significantly in cells that were compromised for mortalin. The effect was observed for both wild-type and mutant p53. In the same cells, p53-Bcl-2 interaction did not show significant change after mortalin silencing. Taken together, the study suggested that mortalin-p53 interaction abrogates p53-Bax complex formation that is required for the apoptotic function of p53 as suggested in earlier studies. ${ }^{28}$ Thus, mortalin silencing by shRNA-2166 led to increased p53-Bax complex formation, resulting in apoptosis.

\section{Discussion}

p53-mediated apoptosis has been shown to serve as a tumor suppression mechanism to eliminate genetically unstable cells. ${ }^{29}$ However, in most of the cancers including HCC, such apoptotic functions are often deregulated either by mutations or by binding to other modulating proteins. Mutant p53 is insufficient for binding to DNA and for transcription-activating function. It blocks endogenous wild-type p53 functions in a dominant-negative manner. ${ }^{30,31}$ Besides mutations, the cytoplasmic sequestration of p53 by its binding proteins has been shown to inactivate p53 functions in cancer cells. These include Parc $^{3}$ adenovirus E1B protein ${ }^{4}$ and small Hsp alphaB-crystallin. ${ }^{5}$ Similar to Parc, ${ }^{3}$ mortalin blocks nuclear translocation of $p 53 .^{19}$ The strategies that can restore the tumor suppression and apoptotic function of p53 are promising for cancer treatment.

Heterogeneity of cancer cells is an established feature. It has been shown that cancer cell lines range from immortal, transformed, malignant and aggressively metastatic phenotypes. It has also been established that cancer cells are under a physiologically stressed condition that may vary from one cancer type to another and among different stages of cancer. ${ }^{29}$ Most cancer cells exhibit high-level expression of Hsp70 family proteins that have crucial roles in tumor 
a
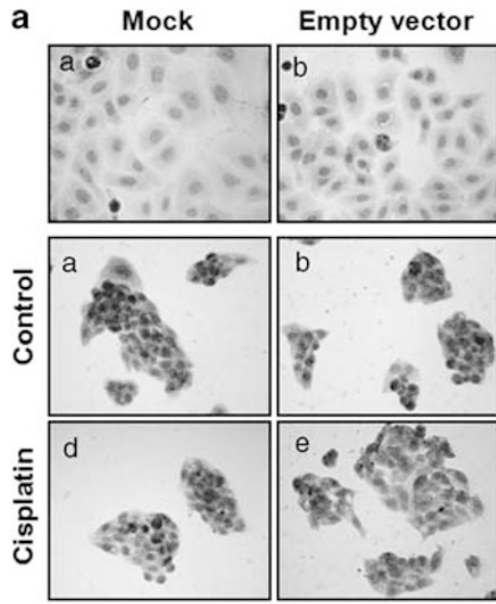

C

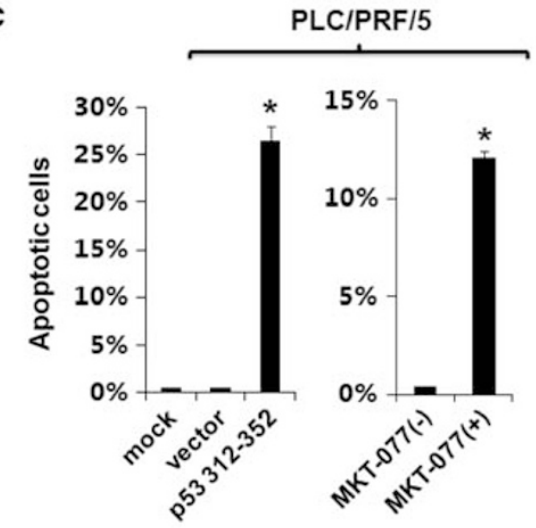

b
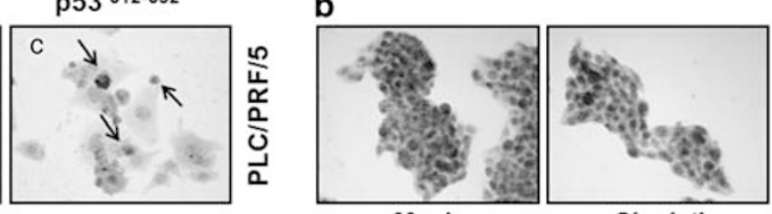

Cisplatin
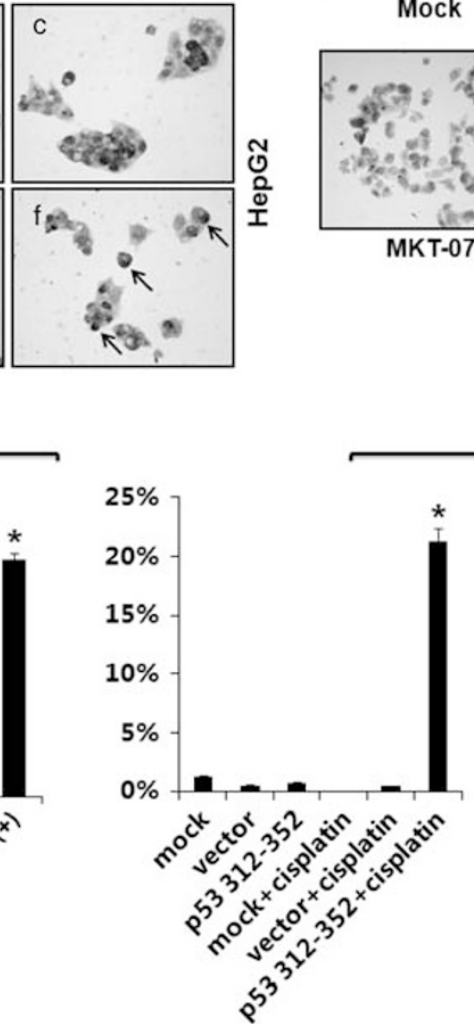

HepG2

HepG2
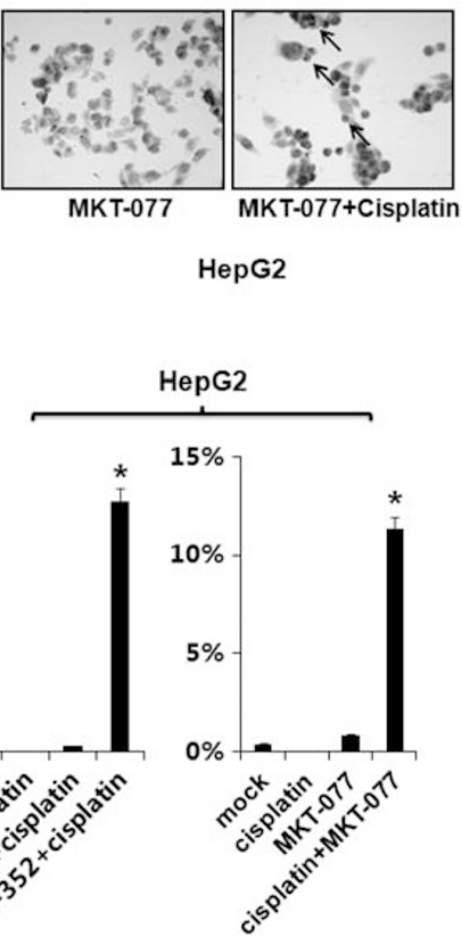

Figure 7 Reactivation of the apoptotic function of $\mathrm{p} 53$ by targeting mortalin-p53 interaction with and without stress. Mortalin-p53 interaction was targeted by mortalin-p53 binding antagonists, mortalin-binding peptide $p 53^{312-352}$ and cationic dye MKT-077. (a) PLC/PRF/5 cells underwent apoptosis in response to the expression of $p 53^{312-352}$ peptide. HepG2 cells (lacking mortain-p53 interactions) were sensitized to p53 $3^{312-352}$-induced apoptosis by cisplatin treatment. (b) HepG2 cells showed no apoptosis in response to either cisplatin or MKT-077 treatment alone. Apoptosis was induced by co-treatment with cisplatin and MKT-077. (c) Quantitation of apoptotic cells was shown $\left({ }^{*} P<0.05\right)$

progression. The level of stress proteins including Hsp70 and Hsp27, and response of p53-Mdm2 feedback loop have been suggested to serve as prognostic and therapeutic markers for cancer cells. ${ }^{32-34}$ Neutralization of Hsp70 through antisense cDNA transfection resulted in tumor death, independent of p53 status. ${ }^{35}$ Mortain-p53 interaction was shown to cause inactivation of both wild-type ${ }^{19-23}$ and mutant p53 (Lu et al, data not shown) activities, including the deregulation of apoptosis in cancer cells by mechanisms involving formation of nuclear Bax/p53 complexes ${ }^{36}$ and their crosstalk with nuclear chaperone, nucleophosmin. ${ }^{37}$ Here, we showed that cancer cells under low stress did not have mortalin-p53 interaction and this was not due to their wild-type p53 status. Both the wild-type and mutant p53 interacted with mortalin in stressed cancer cells. This was validated by using genotoxic stressors such as cisplatin, doxorubicin and hydrogen peroxide. Furthermore, mortalin shRNA-induced apoptosis was exclusive to cancer cells that had phosphorylated p53 (an established marker and barcode of cellular stress). ${ }^{6,7}$ Cells exposed to stress showed mortalin-p53 interaction, and were sensitized to apoptosis by mortalin shRNA and mortalin-p53 binding antagonists, cationic dye (MKT-077) and p53 carboxylterminus peptide ( $\mathrm{p} 53^{312-352}$ ) (Figure 6). The data demonstrated that the mortalin-p53 interaction is a unique phenotype to cancer cells that are under physiologically stressed conditions. It causes inactivation of transcription-dependent and -independent apoptotic functions of p53, and hence constitutes a selective target to reactivate the apoptotic activities of p53. Taken together, we showed for the first time that (i) mortalin binds to p53 and inactivates its apoptotic function in stressed cancer cells and (ii) anti-mortalin molecules, shRNA, mortalin-binding drug and peptides can rescue the apoptotic activity of (both wild-type and mutant) p53 in cancer cells. Thus, targeting of mortalin warrants further investigation in pre-clinical and clinical trial studies.

\section{Materials and Methods}

Cell lines and culture. Human HCC cell lines MHCC97H, MHCC97L, H2P, H2M, PLC/PRF/5, HepG2, Hep3B and an immortalized human hepatocyte liver cell line MIHA ${ }^{38}$ were cultured in Dulbecco's modified Eagle's medium, a high-glucose medium (Invitrogen, Carlsbad, CA, USA), containing 10\% heat-inactivated fetal bovine serum (Invitrogen) in a $5 \% \mathrm{CO}_{2}$ humidified atmosphere at $37^{\circ} \mathrm{C}$. 

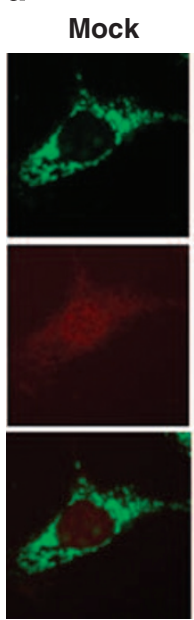

b DAP
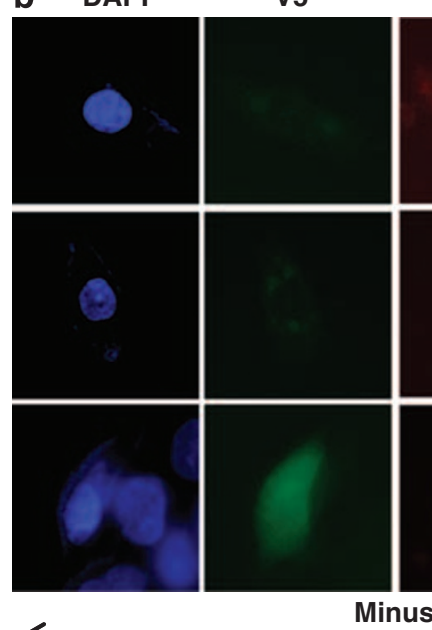

p53

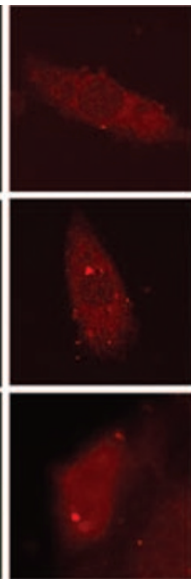

Minus
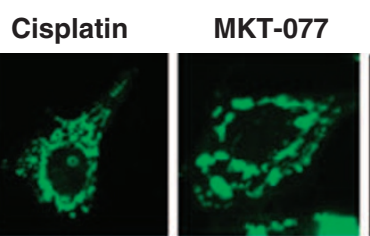

Cisplatin +

MKT-077
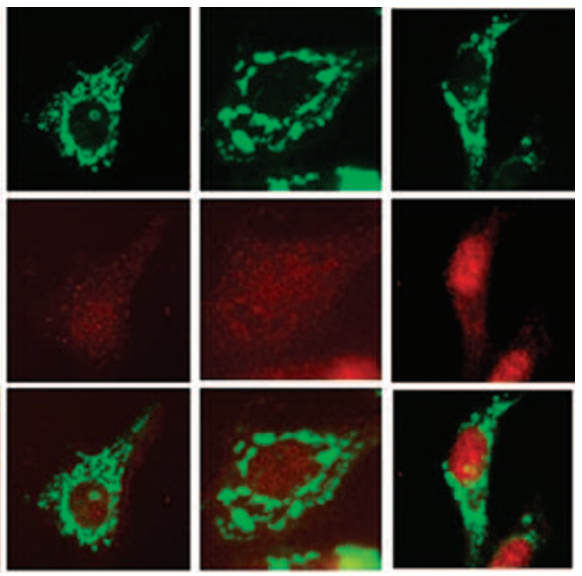

Mortalin

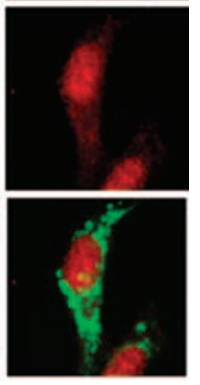

p53

Merge

DAPI

V5

p53
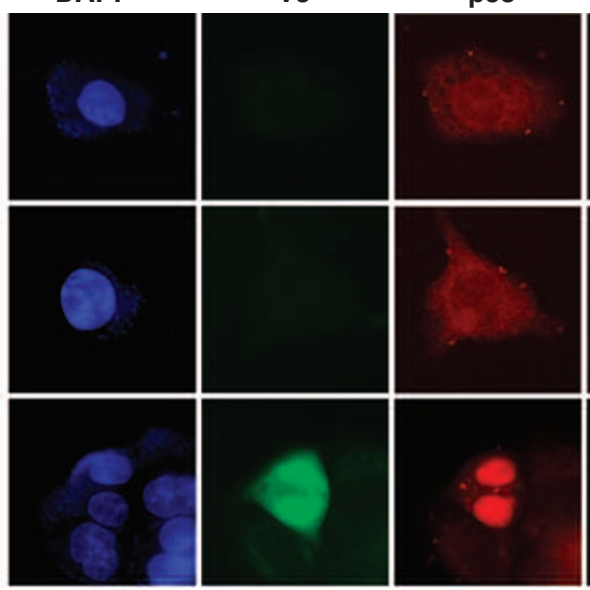

Merge
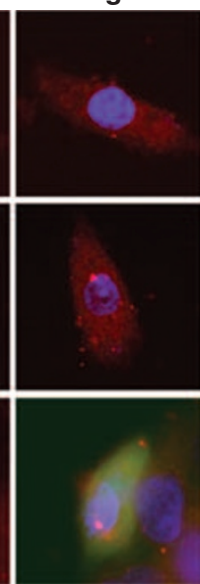

Cisplatin

c
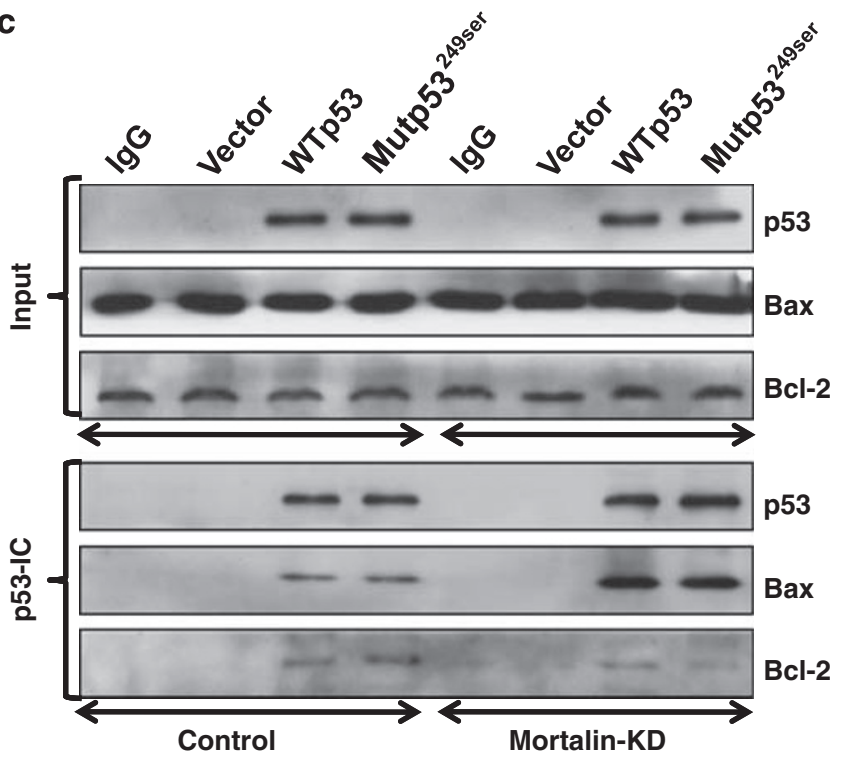

d

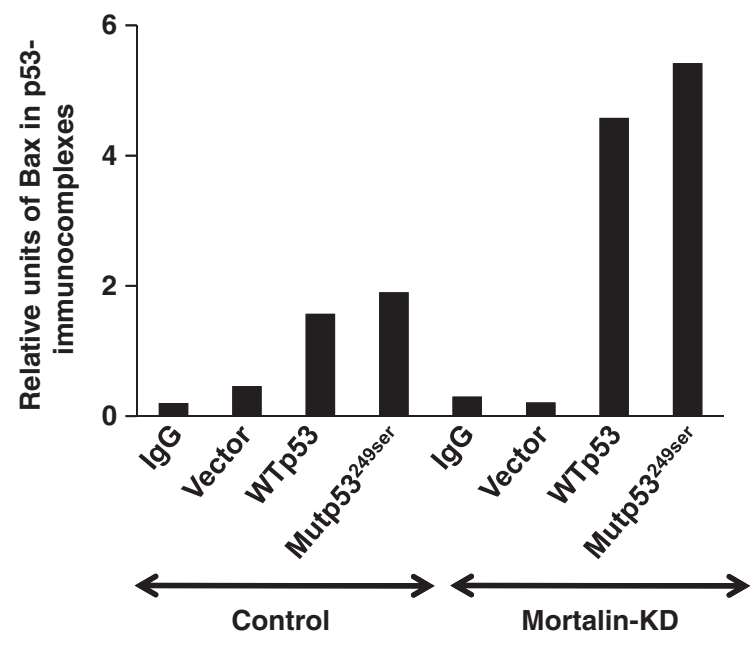

Hep3B

Figure 8 Nuclear accumulation of p53 in HepG2 cells. HepG2 cells treated with either MKT-077 (a) or peptides inhibitor (b) showed nuclear accumulation of p53, only when co-treated with cisplatin. (c) Mortalin knockdown cells (with wild-type or mutant p53) showed increased p53-Bax interaction; the quantitation of Bax present in p53 immunocomplexes in control and mortalin knockdown cells is shown in (d) 


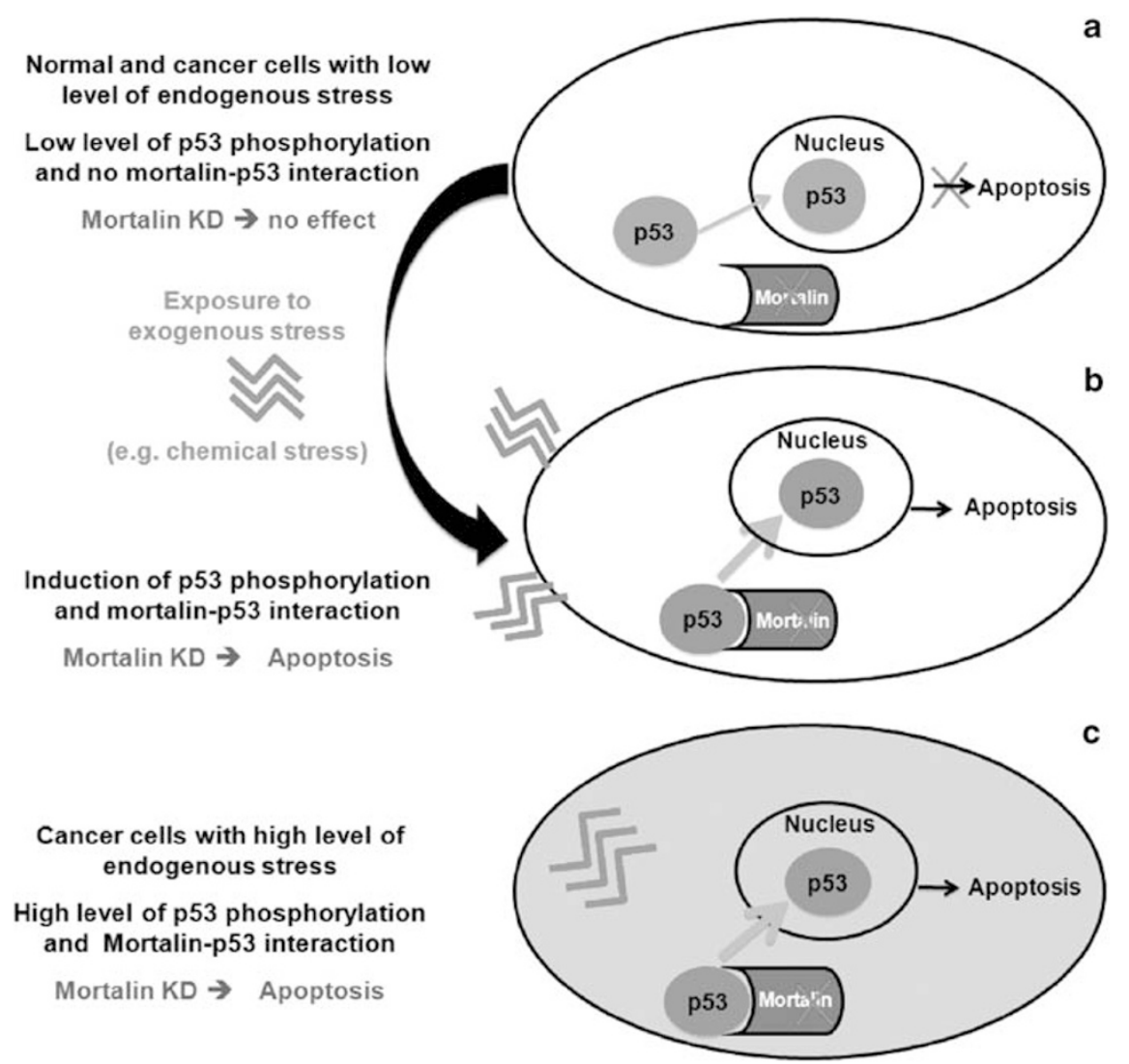

Figure 9 A schematic model showing the effect of mortalin knockdown and nuclear translocation of p53 in cells with different levels of stress. (a) In normal, immortalized and non-malignant cancer cells with low p53 phosphorylation, mortalin does not interact with p53, and hence p53 freely translocates from cytoplasm to nucleus. However, unphosphorylated p53 is inactive, unstable and insufficient for apoptotic activity. Mortalin knockdown has no effect in this category of cells. (b) Exposure of cells to stress (genotoxic or malignancy) causes p53 phosphorylation and accumulation that induces mortalin-p53 interaction. Mortalin silencing by shRNA in this scenario causes nuclear translocation of the phosphorylated p53 that is stable and active, resulting in apoptotic death of cells. (c) In malignant cancer cells with high stress, p53 is heavily phosphorylated and stable. In these cells, mortalin captures p53 in the cytoplasm and blocks its transcriptional activation, growth arrest and apoptotic functions. In this scenario, mortalin knockdown causes nuclear translocation of p53, leading to apoptotic death of cells. According to the proposed model, mortalin-p53 interaction is selective for stressed cancer cells, and hence could serve as a safe target for cancer therapeutics

Antibodies, drugs and plasmids. Antibodies bought were as follows: mortalin (H-155, sc-13967; Santa Cruz, CA, USA), p53 (DO-7; Dako, Carpinteria, CA, USA), phospho-p53 (9919; Cell Signaling, Danvers, MA, USA), actin (clone AC-74, Sigma-Aldrich, St. Louis, MO, USA), caspase-3 (9661 and 9662, Cell Signaling), V5-tag (R960-25, Invitrogen, USA), Hsp70 (4872, Cell Signaling), Bax (2772, Cell Signaling), Bcl-2 (2876, Cell Signaling), MTT (3-(4, 5dimethylthiazol-2-yl)-2,5-diphenyltetrazoliumbromide) (Invitrogen), Pifithrin- $\mu$ (PFT- $\mu$, Merck, Whitehouse Station, NJ, USA), ${ }^{26}$ cisplatin (Sigma-Aldrich), doxorubicin (Sigma-Aldrich), $\mathrm{H}_{2} \mathrm{O}_{2}$ (Sigma-Aldrich) and MKT-077. ${ }^{23}$ The p53 shRNA plasmids were obtained from Addgene (Addgene Cambridge, MA 0213991666, USA) plasmid depository. The Hsp60 and Hsp70 shRNA plasmids were constructed as described previously. ${ }^{39}$

Mortalin shRNA plasmid construction and transfections. The following DNA template oligonucleotides corresponding to HSPA9 gene (GenBank NM_004134) were synthesized: 5'-GCCAGAAGGACAACATATGTTCAAGAGACA TATGTTGTCCTTCTGGCTTITTTGGAAA-3' (2166). These sequences were inserted into the BamHI and Hindlll sites of pSilencer2.1-U6 neo vector (Ambion, Austin, TX, USA) and were verified by DNA sequencing. For all the experiments, $3 \times 10^{5}$ cells were transfected with shRNA ( $2 \mu \mathrm{g}$ for single or $1 \mu \mathrm{g}$ for combinatorial transfection) using the Lipofectamine 2000 (Invitrogen). ${ }^{40}$

Immunoblotting. Cell lysates were prepared in RIPA buffer, electrophoretically separated on $10 \%$ SDS-PAGE gels, electrotransferred to a nylon membrane and probed with the indicated antibody, followed by incubation with horseradish peroxidase (HRP)-conjugated secondary antibody and ECL detection reagents (Amersham Pharmacia Biotech/GE Healthcare, Piscataway, NJ, USA).

Determination of cell viability. Cells were transfected with different vectors as indicated. Twelve hours post-transfection, each group was re-seeded with an equal density of 4000 cells per well in a 96-well plate. For viability assay, $10 \mu \mathrm{l}$ of MTT (5 mg/ml) was added, and plates were placed at $37^{\circ} \mathrm{C}$ for $2 \mathrm{~h}$. In all, $100 \mu \mathrm{l}$ of dimethylsulfoxide (DMSO) was added to each well for cell lysis. Absorbance was measured at $570 \mathrm{~nm}$ with the reference filter $(655 \mathrm{~nm})$. All the experiments were done in triplicates.

TUNEL assay. Cells were grown on coverslips and fixed with $4 \%$ paraformaldehyde in phosphate-buffered saline (PBS) (pH 7.4). The terminal TUNEL assay was carried out following the manufacturer's instructions (11684817910, Roche Applied Science, Indianapolis, IN, USA). Hematoxylin was used as a counterstain.

Treatment of transfected cells with drugs. Cisplatin (1 and $2 \mu \mathrm{g} / \mathrm{ml})$, doxorubicin $(10 \mathrm{ng} / \mathrm{ml})$, hydrogen peroxide $(10 \mu \mathrm{M})$ and MKT-077 $(5 \mu \mathrm{g} / \mathrm{ml})$ treatments were given for $48-72 \mathrm{~h}$.

Co-immunoprecipitation assay. Cell lysates $(500 \mu \mathrm{g}$ protein in $400 \mu \mathrm{l}$ RIPA lysis buffer) were pre-cleared with protein A/G PLUS-Agarose beads (sc-2003, Santa Cruz) and were incubated with anti-mortalin antibody at $4^{\circ} \mathrm{C}$ 
overnight. Immunocomplexes were separated by incubation with protein $A / G$ Agarose beads and were resolved on SDS-PAGE. Immunoblotting was performed with antibodies as indicated.

Immunofluorescence staining. Cells were fixed with $4 \%$ paraformaldehyde in PBS, permeabilized with $0.1 \%$ Triton X-100 for $15 \mathrm{~min}$ immunostained for mortalin and p53 as described ${ }^{19}$ and visualized using an Eclipse E600 image analysis system (Nikon, Tokyo, Japan).

\section{Conflict of interest}

The authors declare no conflict of interest.

Acknowledgements. This work was supported in part by the grants from the NUS seed fund, NMRC grant from the Ministry of Health, Singapore, and grant from the National Institute of Advanced Industrial Science \& Technology (AIST).

1. Kastan MB, Zhan QM, Eldeiry WS, Carrier F, Jacks T, Walsh WV et al. A mammalian cell cycle checkpoint pathway utilizing p53 and GADD45 is defective in ataxia-telangiectasia. Cell 1992; 71: 587-597.

2. Yonish-Rouach E, Resnitzky D, Lotem J, Sachs L, Kimchi A, Oren M. Wild-type p53 induces apoptosis of myeloid leukaemic cells that is inhibited by interleukin-6. Nature 1991; 352: 345-347.

3. Nikolaev AY, Li M, Puskas N, Qin J, Gu W. Parc: a cytoplasmic anchor for p53. Cell 2003; 112: $29-40$

4. Zhao LY, Liao DQ. Sequestration of $p 53$ in the cytoplasm by adenovirus type $12 \mathrm{E} 1 \mathrm{~B} 55$ kilodalton oncoprotein is required for inhibition of p53-mediated apoptosis. J Virol 2003; 77 : 13171-13181

5. Liu S, Li J, Tao Y, Xiao X. Small heat shock protein alphaB-crystallin binds to p53 to sequester its translocation to mitochondria during hydrogen peroxide-induced apoptosis. Biochem Biophys Res Commun 2007; 354: 109-114.

6. Murray-Zmijewski F, Slee EA, Lu X. A complex barcode underlies the heterogeneous response of p53 to stress. Nat Rev Mol Cell Biol 2008; 9: 702-712.

7. Bode AM, Dong Z. Post-translational modification of p53 in tumorigenesis. Nat Rev Cancer 2004; 4: 793-805.

8. Luo J, Su F, Chen D, Shiloh A, Gu W. Deacetylation of p53 modulates its effect on cell growth and apoptosis. Nature 2000; 408: 377-381.

9. Melchior F, Hengst L. SUMO-1 and p53. Cell Cycle 2002; 1: 245-249.

10. Shaw $P$, Freeman J, Bovey R, Iggo R. Regulation of specific DNA binding by p53: evidence for a role for O-glycosylation and charged residues at the carboxy-terminus. Oncogene 1996; 12: 921-930.

11. Wesierska-Gadek J, Bugajska-Schretter A, Cerni C. ADP-ribosylation of p53 tumor suppressor protein: mutant but not wild-type p53 is modified. J Cell Biochem 1996; 62: 90-101.

12. Fuchs SY, Adler V, Buschmann $\mathrm{T}, \mathrm{Wu} \mathrm{X}$, Ronai Z. Mdm2 association with p53 targets its ubiquitination. Oncogene 1998; 17: 2543-2547.

13. Sugito K, Yamane M, Hattori H, Hayashi $Y$, Tohnai I, Ueda M et al. Interaction between hsp70 and hsp40, eukaryotic homologues of DnaK and DnaJ, in human cells expressing mutant-type p53. FEBS Lett 1995; 358: 161-164.

14. Selkirk JK, Merrick BA, Stackhouse BL, He C. Multiple $p 53$ protein isoforms and formation of oligomeric complexes with heat shock proteins Hsp70 and Hsp90 in the human mammary tumor, T47D, cell line. Appl Theor Electrophor 1994; 4: 11-18.

15. Sepehrnia B, Paz IB, Dasgupta G, Momand J. Heat shock protein 84 forms a complex with mutant p53 protein predominantly within a cytoplasmic compartment of the cell. J Biol Chem 1996; 271: 15084-15090.

16. Dundas SR, Lawrie LC, Rooney PH, Murray GI. Mortalin is over-expressed by colorectal adenocarcinomas and correlates with poor survival. J Pathol 2005; 205: 74-81.

17. Wadhwa R, Takano S, Kaur K, Deocaris CC, Pereira-Smith OM, Reddel RR et al. Upregulation of mortalin/mthsp70/Grp75 contributes to human carcinogenesis. Int $J$ Cancer 2006; 118: 2973-2980.
18. YiX, Luk JM, Lee NP, Peng J, Leng X, Guan XY et al. Association of mortalin (HSPA9) with liver cancer metastasis and prediction for early tumor recurrence. Mol Cell Proteomics 2008; 7: 315-325.

19. Kaul SC, Aida S, Yaguchi T, Kaur K, Wadhwa R. Activation of wild type p53 function by its mortalin-binding, cytoplasmically localizing carboxyl terminus peptides. J Biol Chem 2005 280: 39373-39379.

20. Wadhwa R, Takano S, Robert M, Yoshida A, Nomura H, Reddel RR et al. Inactivation of tumor suppressor p53 by mot-2, a hsp70 family member. J Biol Chem 1998; 273 29586-29591.

21. Ma Z, Izumi H, Kanai M, Kabuyama Y, Ahn NG, Fukasawa K. Mortalin controls centrosome duplication via modulating centrosomal localization of p53. Oncogene 2006; 25 $5377-5390$.

22. Kanai M, Ma Z, Izumi H, Kim SH, Mattison CP, Winey M et al. Physical and functional interaction between mortalin and Mps1 kinase. Genes Cells 2007; 12: 797-810.

23. Wadhwa R, Sugihara T, Yoshida A, Nomura H, Reddel RR, Simpson R et al. Selective toxicity of MKT-077 to cancer cells is mediated by its binding to the hsp70 family protein mot-2 and reactivation of p53 function. Cancer Res 2000; 60: 6818-6821.

24. Ran Q, Wadhwa R, Kawai R, Kaul SC, Sifers RN, Bick RJ et al. Extra-mitochondrial localization of mortalin/mthsp70/PBP74/GRP75. Biochem Biophys Res Commun 2000 275: 174-179.

25. Wadhwa R, Taira K, Kaul S C 2002 An hsp70 family chaperone, mortalin: what, when and where? Cell Stress Chaperones 7: 309-316.

26. Strom E, Sathe S, Komarov PG, Chernova OB, Pavlovska I, Shyshynova I et al. Smallmolecule inhibitor of $p 53$ binding to mitochondria protects mice from gamma radiation Nat Chem Biol 2006; 2: 474-479.

27. Leu JI, Pimkina J, Frank A, Murphy ME, George DL. A small molecule inhibitor of inducible heat shock protein 70. Mol Cell 2009; 36: 15-27.

28. Chipuk JE, Kuwana T, Bouchier-Hayes L, Droin NM, Newmeyer DD, Schuler M et al. Direct activation of Bax by $\mathrm{p} 53$ mediates mitochondrial membrane permeabilization and apoptosis. Science 2004; 303: 1010-1014.

29. Lowe SW, Cepero E, Evan G. Intrinsic tumour suppression. Nature 2004; 432: 307-315.

30. Dearth LR, Qian H, Wang T, Baroni TE, Zeng J, Chen SW et al. Inactive full-length p53 mutants lacking dominant wild-type p53 inhibition highlight loss of heterozygosity as an mportant aspect of p53 status in human cancers. Carcinogenesis 2007; 28: 289-298.

31. Kato S, Han SY, Liu W, Otsuka K, Shibata H, Kanamaru R et al. Understanding the function-structure and function-mutation relationships of p53 tumor suppressor protein by high-resolution missense mutation analysis. Proc Natl Acad Sci USA 2003; 100 8424-8429.

32. Ishibashi J, Yamashit $\mathrm{K}$, Ishikawa $T$, Hosokawa $\mathrm{H}$, Sumida $\mathrm{K}$, Nagayama $\mathrm{M}$ et al. The effects inhibiting the proliferation of cancer cells by far-infrared radiation (FIR) are controlled by the basal expression level of heat shock protein (HSP) 70A. Med Oncol 2008; 25: 229-237.

33. Hunziker A, Jensen MH, Krishna S. Stress-specific response of the p53-Mdm2 feedback oop. BMC Syst Biol 2010; 4: 94-98.

34. Luk JM, Lam CT, Siu AFM, Lam BY, Ng IOL, Hu MY et al. Proteomic profiling of hepatocellular carcinoma in Chinese cohort reveals heat-shock proteins (Hsp27, Hsp70 GRP78) up-regulation and their associated prognostic values. Proteomics 2006; 6 1049-1057.

35. Nylandsted J, Wick W, Hirt UA, Brand K, Rohde M, Leist M et al. Eradication of glioblastoma, and breast and colon carcinoma xenografts by Hsp70 depletion. Cancer Res 2002; 62: 7139-7142.

36. Raffo AJ, Kim AL, Fine RL. Formation of nuclear Bax/p53 complexes is associated with chemotherapy induced apoptosis. Oncogene 2000; 19: 6216-6228.

37. Geng Y, Walls KC, Ghosh AP, Akhtar RS, Klocke BJ, Roth KA. Cytoplasmic p53 and activated Bax regulate p53-dependent, transcription-independent neural precursor cell apoptosis. J Histochem Cytochem 2010; 58: 265-275.

38. Brown JJ, Parashar B, Moshage H, Tanaka KE, Engelhardt D, Rabbani E et al. A long-term hepatitis $B$ viremia model generated by transplanting nontumorigenic immortalized human hepatocytes in Rag-2-deficient mice. Hepatology 2000; 31: 173-181.

39. Wadhwa R, Takano S, Kaur K, Aida S, Yaguchi T, Kaul Z et al. Identification and characterization of molecular interactions between mortalin/mtHsp70 and HSP60. Biochem J 2005; 391: 185-190.

40. Liu LX, Lee NP, Chan VW, Xue W, Zender L et al. Targeting cadherin-17 inactivates Wn signaling and inhibits tumor growth in liver carcinoma. Hepatology 2009; 50: 1453-1463. 